\title{
EDUCAÇÃO AMBIENTAL E O PROCESSO DE INTERDISCIPLINARIDADE NO AMBIENTE ESCOLAR
}

\author{
Nilziane Costa Marvila ${ }^{1}$ \\ Luana Frigulha Guisso ${ }^{2}$
}

Resumo: Este artigo teve como objetivo compreender os desafios que tangem a inserção da Educação Ambiental no ambiente escolar e seu processo de interdisciplinaridade e Identificar as metodologias que os educadores utilizam para inserir a temática. Para a pesquisa foram analisados professores de uma escola polo do município de Presidente Kennedy, Espírito Santo. Com característica de pesquisa qualitativa apresenta como principal instrumento de coleta de dados o questionário aberto, em que os pesquisados tiveram a possibilidade de percorrer o tema proposto, sem respostas ou categorias preestabelecidas.

Palavras-chave: Educação Ambiental; Interdisciplinaridade; Desafio; Metodologias.

1 Faculdade Vale do Cricaré. E-mail: nilzianecosta19@hotmail.com

2 Universidade Federal do Espírito Santo. E-mail: Ifgd10@hotmail.com

Revbea, São Paulo, V. 14, № 4: 340-350, 2019. 


\section{Introdução}

A educação é um processo contínuo para o desenvolvimento intelectual e moral do indivíduo, pois promove a integração do ser humano na sociedade, despertando a capacidades e competências nas atividades do cidadão (VIANNA, 2008). Com o objetivo a formação de pessoas críticas, ativas, criativas e pesquisadoras, na busca da construção da autonomia (THOMAZ, OLIVEIRA; 2009), trata-se de um processo que possibilita ao ser humano refletir e intervir sobre a própria realidade.

A escola é o local privilegiado para essa aprendizagem, o papel da escola é socializar o conhecimento e atuar na formação moral dos alunos, promovendo o seu pleno desenvolvimento, ajudando o aluno a perceber a correlação dos fatos e a ter uma visão holística e integral do mundo em que vive (ROSA; SILVA; LEITE, 2009). Neste sentido, pode-se definir a escola como um ambiente transformador e incentivador da prática social do indivíduo, um ambiente rico para o desenvolvimento da Educação Ambiental (EA).

A Educação Ambiental é considerada como agente difusor dos conhecimentos sobre o meio ambiente e indutor de mudança dos hábitos e comportamentos compatíveis com a preservação, voltados principalmente para a educação popular como forma de sensibilização da população sobre a importância do meio ambiente (CARVALHO, 1992).

Em 1997, o Ministério da Educação e Cultura (MEC) publicou os Parâmetros Curriculares Nacionais (PCNs) que enfatizaram o meio ambiente e direcionaram a educação brasileira nas atividades de Educação Ambiental, tornando-a uma temática transversal e a ser desenvolvida de forma Interdisciplinar. A principal função foi a de contribuir para a formação de cidadãos conscientes, aptos a decidir e a atuar na realidade socioambiental e no bem-estar do indivíduo e da sociedade, além de impulsionar a escola a trabalhar com atitudes, com formação de valores, com o ensino e a aprendizagem de habilidades e procedimentos com o tema Meio Ambiente.

O papel do professor é de suma importância para a inserção da Educação Ambiental, por meio dele, mudanças, práticas, estratégias e didáticas interdisciplinares são delineadas. Neste artigo buscou-se compreender os desafios que tangem a inserção da Educação Ambiental no ambiente escolar e seu processo de interdisciplinaridade e Identificar as metodologias que os educadores do município de Presidente Kennedy utilizam para inserir a temática.

\section{Desenvolvimento}

A metodologia pode ser entendida como a postura do educador diante da realidade, como a articulação de uma teoria de compreensão e interpretação da realidade a uma prática específica, ou seja, a prática pedagógica que demanda uma intencionalidade (VASCONCELLOS, 2002). Esta implica em algumas tarefas indissociáveis: partir da prática (assumindo-a 
como um desafio); refletir sobre a prática (buscando conhecer seus determinantes e captar sua essência, projetando alternativas de ação); e transformar a prática (atuando de forma organizada na direção desejada) (MORAES, 2017). Com isso, as metodologias utilizadas pelos professores devem estar relacionadas com a concepção pedagógica. É necessário rever constantemente a prática pedagógica e valorizar a produção crítica e criativa do saber, proporcionando ao aluno defrontar com o cotidiano, de modo, que venha a se transformar com as situações didáticas propiciando autonomia e consciência crítica. Desta forma, deve-se "organizar as interações e atividades de modo que cada aluno se defronte constantemente com situações didáticas que Ihe sejam as mais fecundas" (PERRENOUD, 1995, p. 28).

Os temas ambientais vêm superando a ideia de que a Educação Ambiental tem como tarefa a transmissão de informações sobre os diferentes temas e a Educação Ambiental não se restringe à dimensão informativa, ela busca cumprir a tarefa educativa, da formação plena, crítica e reflexiva do sujeito ecológico (CARVALHO, 2004). Sendo assim, nota-se que a Educação Ambiental, como ferramenta da educação, tem que ser desenvolvida como uma "prática", e, para isso, todas as pessoas que lidam ou trabalham, direta ou indiretamente, com uma escola precisam estar preparadas. Então, a prática da Educação Ambiental precisa estar interligada com todas as disciplinas regulares, conforme previsto nos Parâmetros Curriculares Nacionais, pois esta estimula a curiosidade, o senso de aventura e as descobertas.

Conforme afirma Japiassú (1976, p. 82):

A interdisciplinaridade é algo a ser vivido, enquanto atitude de espírito [...] feita de curiosidade, de abertura, do senso de aventura e descoberta, e exerce um movimento de conhecimento capaz de intuir relações. É, nesse sentido, uma prática individual. Mas também é prática coletiva, onde se expressa como atitude de abertura ao diálogo com outras disciplinas.

Logo, para que a escola funcione bem, é necessário que se utilizem métodos de ensino eficazes, por serem eles os responsáveis por estimular a atividade e a iniciativa dos alunos, porém, sem abrir mão da iniciativa do professor. O método deve favorecer o diálogo dos alunos entre si e com o professor, mas sem deixar de valorizar o diálogo com a cultura acumulada historicamente (SAVIANI, 1999). Deste modo, se deixa de lado o modelo de prática pedagógica em que prevalece apenas o repasse verbal de conteúdo do professor para o aluno, para que ele o reproduza fielmente na realização de exercícios propostos, em que o aluno aprendeu a reproduzir, mas não aprendeu o conteúdo (BRASIL, 1997). É válido ressaltar que é necessário buscar alternativas para que, de fato, haja contribuição para a aprendizagem ambiental. 


\section{Metodologia}

Esta pesquisa caracteriza-se como "uma pesquisa de campo de caráter qualitativo exploratório", conforme explicita Gil (1991, p. 75), pois a pesquisa tende a esquadrinhar informações sobre a realidade analisada, proporcionando aos entrevistados expor as perspectivas sobre o objeto de estudo. Assim sendo, um fenômeno pode ser concebido por meio de uma concepção integrada.

Para a coleta de dados foi utilizada a aplicação de questionário aberto que, de acordo com Gil (1999, p. 128), pode ser definido "como a técnica de investigação [...], tendo por objetivo o conhecimento de opiniões, crenças, sentimentos, interesses, expectativas, situações vivenciadas etc.".

O público-alvo da pesquisa foi formado pelos professores de uma escola polo do município de Presidente Kennedy, a EMEIEF de Jaqueira "Bery Barreto de Araújo". A escolha das escolas polo deu-se pelo fato de que estas são núcleos de ensino, ou seja, possuem maiores números de estudantes e professores que atuam em seu sistema, além de abranger o Ensino Infantil e Fundamental.

No estudo foram envolvidos 22 educadores da EMEIEF de Jaqueira "Bery Barreto de Araújo" situada no município de Presidente Kennedy, Espírito Santo. Atualmente, Presidente Kennedy é considerado o município que mais investe recursos em educação e a terceira cidade mais bem avaliada no Estado, segundo o Índice de Desenvolvimento da Educação Básica (Ideb). Além disso, os dados divulgados pelo MEC no ano de 2015, indicam também que desde 2013 a cidade é a que mais investe em educação por aluno em todo o Espírito Santo (PREFEITURA DE PRESIDENTE KENNEDY, 2018).

\section{Resultados e discussões}

Dos 22 professores que atuam na instituição de ensino, dois lecionam Arte equivalendo a $9 \%$, outros três Ciências equivalendo a $14 \%$, dois Educação Física equivalendo a $9 \%$, mais três professores lecionam Geografia equivalendo a $14 \%$ e mais três lecionam História equivalendo a $14 \%$. Enquanto isso, apenas um professor dá aulas de Inglês equivalendo a $5 \%$, quatro dão aulas de Língua Portuguesa equivalendo a $18 \%$ e quatro de Matemática equivalendo a $18 \%$ do total. $O$ maior percentual está relacionado às disciplinas Língua Portuguesa e Matemática.

$\mathrm{Na}$ primeira questão, foi abordado o quesito sobre a realização do trabalho dos educadores, em que os profissionais foram questionados se desenvolvem a Educação Ambiental em sala de aula e qual a metodologia que estes utilizam, destacaram-se as afirmativas: 
"Sim, trabalho com materiais recicláveis, assim mostro ao aluno que o material que iria para o lixo terá outra utilidade" Professor: (Arte).

"Sim, utilizo aulas no laboratório de informática e abordo a Educação Ambiental" Professor: (Geografia).

"Sim, o desenvolvimento da Educação Ambiental em sala está relacionado com projetos e aulas expositivas" Professor: (História).

"Sim, trabalho Educação Ambiental através de interpretações de textos e avaliações" Professor: (Língua Portuguesa).

"Sim, através de projetos e pesquisas" Professor: (Matemática).

Ficou registrado que 16 professores, cerca de $73 \%$ dos entrevistados, asseguraram que a EA está sendo desenvolvida pelos entrevistados. . As práticas de Educação Ambiental utilizada por esses educadores são diversas (materiais recicláveis, projetos, debates, textos interpretativos, pesquisas, trabalhos em grupos, aulas expositivas e aula no laboratório de informática). Neste sentido, entende-se por práticas pedagógicas, ações educativas ancoradas por teoria e prática por meio do desenvolvimento e variação das fontes autênticas de saberes e a necessária harmonia entre o saber fazer e o saber ser pedagógico (FREIRE, 1996).

Diante disso, é assertivo pensar que a abordagem das questões ambientais, na prática pedagógica, deve colaborar para o exercício da cidadania estimulando a mudança de comportamento, proporcionando a construção de novos sistemas de valores com relação aos seres vivos e ao ambiente que ocupam. Dessa forma, a Educação Ambiental é um processo que é internalizado e, assim, proporciona sentido aos ensinamentos das disciplinas curriculares. Contudo, a Educação Ambiental não é apenas uma educação de conteúdos, mas, especialmente, de postura, de aquisição de valores da vida e da ética, da comunicação e da liberdade (FREIRE, 2003).

Em relação a mesma questão, seis (6) entrevistados afirmaram que:

"Não desenvolvo a Educação Ambiental, mas acredito que pode ser trabalhada através de jogos, dramatização e aulas de demonstrações" Professor : (Artes).

"Não desenvolvo, mas deveria ser trabalhada através de projetos" Professor: (Educação Física).

"Não, a Educação Ambiental pode ser trabalhada através de projetos e dinâmicas" Professor: (História).

"Não, a Educação Ambiental pode ser desenvolvida através de aulas demonstrativas, aula de campo, trabalhos e projetos" Professor: (Inglês). 
"Não, pode ser trabalhada através de livros, músicas e filmes" Professor: (Língua Portuguesa).

"Não, mas pode ser trabalhada através de aulas dinâmicas e através de trabalhos em sala de aula" Professor: (Matemática).

Cerca de seis (6) professores, $27 \%$ dos entrevistados não desenvolvem a Educação Ambiental em sua aula, mas afirmam que teriam possibilidade de desenvolver a temática no ambiente escolar. Demonstrando que "a dimensão ambiental é percebida, mas não se inscreve em uma prática pedagógica transformadora" (SATO, 2001, p. 19).

A dificuldade de inserir a Educação Ambiental está relacionada à falta de aprofundamento nas questões educativas. Conforme afirma Loureiro (2002, p. 31):

Os profissionais e instituições envolvidos em Educação Ambiental precisam se aprofundar mais nas questões educativas para serem capazes de, a partir de uma dada realidade, que se insere na estrutura de poder na sociedade, elaborarem conjuntamente com a comunidade alternativas viáveis e transformadoras.

Logo, pode-se afirmar que o educador precisa conhecer as questões ambientais para, assim, inserir no contexto educacional, elaborando alternativas para que haja a transformação no indivíduo. Portanto, é fácil perceber que o papel dos professores é primordial para impulsionar as transformações de uma educação que precisa levar em consideração a questão do desenvolvimento sustentável. Neste sentido, existe a necessidade de o professor assumir uma postura reflexiva para, numa perspectiva crítica, desenvolver práticas que articulem a educação e o meio ambiente. Além disso, é preciso ter uma atuação ecológica sustentada por princípios de criatividade, possibilitando a sensibilização de seus alunos e uma crescente participação (JACOBI, 2005).

$\mathrm{Na}$ segunda questão foi mencionado a respeito se a Educação Ambiental está sendo desenvolvida de forma Interdisciplinar pela escola, as principais respostas foram:

"Sim, através de projetos que acontecem na escola" Professor: (Ciências).

Sim, através de projetos esporádicos" Professor: (Educação Física).

“Sim, através de projetos e pesquisas" Professor: (História). 
"Sim há uma participação efetiva de todos os professores, em realização de projetos, pesquisas, entre outros" Professor: (Língua Portuguesa).

"Sim, através de projetos e da adequação nos conteúdos" Professor: (Matemática).

16 professores asseguraram que sim. Isto corresponde a cerca de $73 \%$ dos entrevistados. A interdisciplinaridade escolar, para Fazenda (1991), é uma atitude tomada pelo profissional de ensino, na tentativa de buscar alternativas para conhecer mais além da própria área. Essa busca leva a romper com as barreiras entre as disciplinas por meio do diálogo constante entre os professores, com a criação de projetos coletivos em que todos possam trabalhar integrando teorias, métodos e práticas. Significa a substituição de uma concepção fragmentária e individualista do ser humano, para uma visão do ser humano em constante processo de transformação, que necessita da integração social para se desenvolver.

A Educação Ambiental, não deve ser fragmentada, mas deve refletir a interdisciplinaridade de conteúdos (MELLER, 1997). Dessa forma, acredita-se que a interdisciplinaridade só será eficaz se possuir metas educacionais previamente estabelecidas e compartilhadas pelos profissionais da unidade escolar, visando garantir a construção de um conhecimento globalizante, rompendo com os limites das disciplinas.

Os projetos e pesquisas foram mencionados pelos entrevistados, como a forma que a interdisciplinaridade ocorre na escola. Segundo Libâneo (1994), o processo de ensino se caracteriza pela combinação de atividades do professor e dos alunos, ou seja, o professor dirige o estudo das matérias e, assim, os alunos atingem progressivamente o desenvolvimento de suas capacidades mentais. É importante ressaltar que o direcionamento do processo de ensino necessita do conhecimento dos princípios, diretrizes e métodos.

E por fim, na questão seguinte foi perguntado quais os desafios encontrados por esses professores para inserir a Educação Ambiental, destacaram-se as respostas:

"Acredito que a falta de suporte da escola e a falta de materiais didáticos" Professor: (Arte).

"A falta de materiais para trabalharmos a Educação Ambiental e a falta de apoio para algumas práticas" Professor: (Ciências).

"O maior desafio é a falta de formação continuada para os professores, pois sem aprendizado não há educação" Professor: (História).

A Educação Ambiental só pode ser transmitida aos alunos, se houver formação continuada para nós educadores. Há uma falta de formação" Professor: (Inglês) 
"Falta de tempo adequado devido ao currículo extenso que temos que seguir" Professor: (Geografia).

"O grande número de conteúdos no currículo, que impede o aprofundamento da Educação Ambiental" Professor: (Língua Portuguesa).

Cerca de nove (9) professores, o equivalente a $41 \%$ dos entrevistados, alegaram que a falta de apoio da escola e a falta de materiais para trabalhar com a temática, também são outros desafios que esses profissionais encontram na rotina escolar. A estrutura escolar é muito importante para que o aprendizado ocorra, tendo em vista que recursos didáticos precários são algumas das mazelas ainda encontradas na maioria das escolas públicas e que, portanto, determinam condições ruins de trabalho para os professores e os funcionários. Longe de estarem satisfeitos os professores, em geral, sentem-se cansados e frustrados. Dessa maneira, o educador deve também quebrar os paradigmas estruturais da escola e propor metodologias que envolva principalmente o aprendizado do educando em Educação Ambiental, pois de acordo com Nóvoa (2007, p. 6) na escola "tudo é importante, desde que não se esqueça de que a prioridade primeira dos docentes é a aprendizagem dos alunos".

A falta de formação continuada também foi mencionada por seis (6) dos professores entrevistados nesta pesquisa, o equivalente a $27 \%$ dos respondentes. Segundo Carvalho (2006, p. 7), "a formação/capacitação dos professores se apresenta como uma das dificuldades para se alcançar maior sucesso com os projetos de Educação Ambiental [sic] na educação formal". Com isso, para que a Educação Ambiental tenha êxito é necessário que os profissionais da educação e a sociedade tenham subsídios para colocá-la em prática. Infelizmente, a escola ainda possui dificuldades para transmitir este conteúdo, principalmente os educadores que não possuem formação suficiente.

Entende-se, portanto, que os cursos de capacitação promovem para os professores a construção de uma identidade profissional e a reflexão de sua prática pedagógica. $E$, além de ser um investimento pessoal, a formação continuada também acaba culminando na aprendizagem dos educandos, pois se houver maior preparo deste educador, maior êxito este profissional terá na abordagem e prática da Educação Ambiental. Todavia, como explicita Tristão (2007), a formação deve introduzir a Educação Ambiental, sem perder a abordagem vivencial, humanística e transformadora, envolvendo todos/as, professores/as, alunos/as, comunidades e meio ambiente, em uma dinâmica complexa, que resulta da diversidade na formação de um padrão fundamental para vida. Atualmente existem diversas formas de capacitação. Porém, é necessário incluir a realidade de vida com enfoque na formação humana, proporcionando a transformação do indivíduo e a participação de todos neste processo. 
Cerca de sete (7) professores, $32 \%$ dos entrevistados afirmaram que 0 currículo extenso e a falta de tempo foram considerados entre os entrevistados como um dos desafios para inserir a Educação Ambiental. De acordo com Sacristán (1998, p. 166-167), o "[...] professor não decide sua ação no vazio, mas no contexto da realidade de um local de trabalho, numa instituição que tem suas normas de funcionamento marcadas às vezes pela administração, pela política curricular, pelos órgãos de governo de uma escola ou pela simples tradição que aceita sem discutir". Na opinião dos docentes, esta situação decorre da falta de tempo devido à intensificação do trabalho que lhes é solicitado e a características organizacionais da própria escola ou município, apontam também algumas dificuldades no próprio processo de implementação do currículo em aplicar os conteúdos e inserir a Educação Ambiental.

\section{Considerações finais}

A Educação Ambiental, ainda hoje, enfrenta alguns desafios como a questão do currículo, a falta de apoio da escola, os materiais didáticos e a falta de formação, que são os principais obstáculos encontrados pelos educadores. Muitos professores não recebem formação adequada para abordar o tema nas disciplinas, além da própria ausência de um projeto pedagógico consolidador referente à questão ambiental.

Necessita-se de mais envolvimento da comunidade escolar. Para que a Educação Ambiental seja praticada na sala de aula com os alunos, é necessário um suporte da equipe pedagógica com os professores para que possam ir além da teoria. É preciso ter como objetivo levar os educandos a concentrar a atenção, a aguçar a percepção e a ter um contato mais profundo com a natureza, já que a experiência é essencial para a mudança de comportamento em relação ao mundo.

O educador ambiental deve procurar colocar os alunos em situações que sejam formadoras. As práticas pedagógicas proporcionam aos educadores condições para que possam trabalhar temas e atividades de Educação Ambiental no ambiente escolar, que incentivem a mudança de hábitos e valores ambientais e proporcione a construção de uma consciência crítica e participativa de seus educandos.

A interdisciplinaridade também necessita ser aplicada no ambiente escolar, superando o modelo fragmentado, fundado no isolamento de conteúdos. É necessária uma proposta interdisciplinar eficaz, aproximando os alunos da vida real, estimulando a responsabilidade dos indivíduos acerca da preservação do planeta. 


\section{Referências}

RASIL, Ministério da Educação. Parâmetros Curriculares Nacionais. Brasília: MEC, 1997.

CARVALHO, A.M. Uma metodologia de pesquisa para estudar os processos de ensino e aprendizagem em salas de aula. In: SANTOS, F.M.T.; GRECA, I.M. (Orgs.). A pesquisa em ensino de ciências no Brasil e suas metodologias. ljuí: Unijuí, 2006. p. 13-48.

CARVALHO, I.C.M. Educação, meio ambiente e ação política. Meio ambiente e democracia. Rio de Janeiro: Ibase, p. 32-42, 1992.

CARVALHO, I.C.M. Educação Ambiental: a formação do sujeito ecológico. São Paulo: Cortez, 2004.

FAZENDA, I. Práticas interdisciplinares na escola. Cortez Editora, 1991.

FREIRE, P. Educação e atualidade brasileira. São Paulo: Cortez, Instituto Paulo Freire. 2003.

FREIRE, P. Pedagogia da autonomia: Saberes necessários à prática educativa. São Paulo: Paz e Terra, 1996.

GIL, A.C. Como elaborar projetos de pesquisa. 3. ed. São Paulo: Atlas, 1991.

GIL, A.C. Métodos e técnicas de pesquisa social. 5. ed. São Paulo: Atlas, 1999.

JACOBI, P.R. Educação Ambiental: o desafio da construção de um pensamento crítico, complexo e reflexivo. 2005.

JAPIASSÚ, H. Interdisciplinaridade e patologia do saber. São Paulo: Imago, 1976.

LIBÂNEO, J.C. Fundamentos teóricos e práticos do trabalho docente: estudo introdutório sobre pedagogia e didática. São Paulo: Tese de Doutorado, 1990.

LOUREIRO, C.F.B. Educação Ambiental Crítica: Príncipios Teóricos e Metodológicos. $1^{\mathrm{a}}$ ed. Rio de Janeiro: Hotbook, 2002.

MELLER, C.B. Educação Ambiental como possibilidade para superação da fragmentação do trabalho escolar. Espaços da Escola, Ijuí, v. 4, n. 26, p. 3949, 1997.

MORAES, J.P.; FONTOURA PAIM, C. O ensino da administração: práticas pedagógicas e seus impactos no desempenho profissional na visão dos formandos de graduação em administração de uma instituição privada na cidade de Porto Alegre (RS). CAMINE: Caminhos da Educação = Camine: Ways of Education, v. 9, n. 2, p. 96-113, 2017.

NÓVOA, A. O regresso dos professores. 2007.

PERRENOUD, P. Ofício de aluno e sentido do trabalho escolar. Porto: Porto Editora, 1995. 
PREFEITURA MUNICIPAL DE PRESIDENTE KENNEDY. Disponível em: $<$ https://www.presidentekennedy.es.gov.br/>. Acesso em: dez. 2018.

ROSA, L.G; SILVA, M.M.P.; LEITE, V.D. Educação Ambiental em uma Escola de Formação Inicial de nível médio: estratégias e desafios do processo de sensibilização. REMEA-Revista Eletrônica do Mestrado em Educação Ambiental, v. 22, 2009.

SACRISTÁN, J. G. Currículo, uma reflexão sobre a prática.3. ed. Porto Alegre: Artmed, 1998.

SAVIANI, D. Escola e democracia: teorias da educação, curvatura da vara, onze teses sobre educação e política. 32 ed. São Paulo: Cortez/Autores Associados, 1999.

THOMAZ, L; OLIVEIRA, R.C. A educação e a formação do cidadão crítico, autônomo e participativo. Dia-a-dia Educação, p. 1-25, 2009.

TRISTÃO, M. Espaços/tempos de formação em Educação Ambiental. In: GUERRA, A.F.S.; TAGLIEBER, J.E.. Educação Ambiental: fundamentos, práticas e desafios. Itajaí: Universidade do Vale do Itajaí, p. 37-51, 2007.

VASCONCELOS, E.M. Complexidade e Pesquisa Interdisciplinar: epistemologia e metodologia operativa. Petrópolis, RJ: Vozes, 2002.

VIANA, N. Educação, Sociedade e Autogestão Pedagógica. Revista Urutágua: revista acadêmica multidisciplinar, Maringá, n. 16, p. 37-46, ago./set./out./nov. 2008. 